\title{
Implementasi Strategi Cooperative Learning Tipe Jigsaw dalam Pembelajaran Akidah Akhlak Kelas V MIN Bangka Belitung Pontianak
}

\author{
Firmansyah \\ FTIK IAIN Pontianak \\ firmanhabas@gmail.com \\ Akhmad Zaini \\ FTIK IAIN Pontianak \\ zeyzey1991@gmail.com
}

\begin{abstract}
Abstrak
Penelitian ini dilatar belakangi oleh adanya permasalahan yang terjadi pada MIN Bangka Belitung Pontianak seperti guru kurang melibatkan siswa dalam materi pembelajaran, guru cenderung menyampaikan materi dengan menggunakan metode ceramah tanpa adanya variasi sehingga menyebabkan kejenuhan dalam belajar, guru kurang memahami dalam tentang memilih dan menentukan strategi cooperative learning tife jigsawyang tepat sehingga berdampak pada terciptanya proses pembelajara yang lebih baik. Penelitian bertujuan untukmengetahui: perencanaan, langkah-langkah, dan evaluasi dalam pembelajaran Materi Aqidah dengan Strategi Cooperative Tipe Jigsaw dalam pembelajaran Akidah Akhlak Materi Sikap pada guru di Kelas V MIN Bangka Belitung Pontianak Tahun Pelajaran 2017/2018. Hasil penelitian ini menunjukkan: Perencanaan Strategi Cooperative Learning Tipe Jigsawdalam Pembelajaran Akidah Akhlak Pada Materi Akhlak Tercela di Kelas V MIN Bangka Belitung Pontianak dengan lebih baik dan siswa lebih aktif dalam proses pembelajaran; langkah-langkah strategi cooperative learning tipe jigsaw dalam materi sikap siswa di sekolahdi kelas V MIN dibagi menjadi 5 kelompok, setiap kelompok diksih materi pembelajaran, dan siswa mendiskusikan dengan materi tersebut; Pelaksanaan evaluasi proses dan hasil kegiatan pembelajaran yang menggunakan langkah strategi cooperative learning tipe jigsaw dalam materi sikap siswa di sekolahdi kelas V MIN Negeri Bangka Belitung Pontianak adalah menggunakan tes tertulis dan tes lisan juga mengunakan penilain proses dari observasi siswa saat proses pembelajaran atau setelah mata kuliah selesai.
\end{abstract}

Kata Kunci: Implentasi; Strategi Cooperative Learning; Tipe Jigsaw 


\section{PENDAHULUAN}

Model Pemebelajaran Cooperative Learning Tipe Jigsaw adalah sebuah model belajar kooperatif yang menitik beratkan kepada kerja kelompok siswa dalam bentuk kelompok kecil, seperti yang diungkapkan Lie, bahwa pembelajaran Cooperative Learningtipe Jigsaw ini merupakan model belajar kooperatif dengan cara siswa belajar dalam kelompok kecil yang terdiri atas empat sampai dengan enam orang secara heterogen dan siswa bekerja sama saling ketergantungan positif dan bertanggung jawab secara mandiri. ${ }^{1}$

Strategi Pembelajaran Jigsaw ini siswa memiliki banyak kesempatan untuk mengemukakan pendapat, dan mengelolah informasi yang didapat dan dapat meningkatkan keterampilan berkomunikasi, anggota kelompok bertanggung jawab atas keberhasilan kelompoknya dan ketuntasan bagian materi yang dipelajari dan dapat menyampaikan kepada kelompoknya. ${ }^{2}$ Langkah-langkah Model Pembelajaran Kooperatif Jigsaw. Menurut Rusman model pembelajaran jigsaw ini dikenal juga dengan kooperatif para ahli. Karena anggota setiap kelompok dihadapkan pada permasalahan yang berbeda. Namun, permasalahan yang dihadapi setiap kelompok sama, kita sebut sebagai team ahli yang bertugas membahas permasalahan yang dihadapi. Selanjutnya, hasil pembahasan itu di bawah kekelompok asal dan disampaikan pada anggota kelompoknya.

Sedangkan pembelajaran kooperatiftipe jigsaw pertama kali dikembangkan oleh Aronson dan di Universitas Texas. Model pembelajaran kooperatif tipe jigsaw merupakan model pembelajaran kooperatif,siswa belajar dalam kelompok kecil yang terdiri dari 4-5 orang dengan memperhatikan kehetorogenan, bekerja sama positif dan setiap anggota bertanggung jawab untuk mempelajari masalah tertentu dari materi yang

\footnotetext{
${ }^{1}$ Anita Lie. Cooperative Learning: Mempraktekkan Cooperative Learning di RuangRuang Kelas, (Jakarta : PT. Grasindo, 2004), 73.

2 Rusman. Seri Manajemen Sekolah Bermutu Model-Model Pembelajaran Mengembangkan Profesionalisme Guru, (Jakarta; PT. Raja Grafindo Persada, 2018), 203.
} 
diberikan dan menyampaikan matertitersebut kepada anggota kelompok yang pada model pembembelajaran kooperatif tipejigsaw, terdapat kelompok asal dan kelompok ahli yaitu kelompok induk siswa yang beranggotakan siswa dengan kemampuan, asal, dan latar belakang keluarga yang beragam.kelompok asal gabungan dari beberapa ahli, kelompok ahli yaitu yaitu kelompok siswa yang terdiri anggota kelompok asal yang berbeda yang ditugaskan untuk mempelajari dan mendalami topik tertentudan menyelesaikan tugas-tugas yang berhubungan dengan topiknya untuk kemudian dijelaskan kepada anggota kelompok asal. Siswa diminati untuk membaca suatu materi dan diberi lembar ahli (expert sheet) yang memuat topik-topik berbeda untuk tiap anggota tim yang harus dipelajari pada saat membaca. Apabila siswa telah selesai membaca, selanjutnya dari tim berbeda dengan topik yang sama bertemu (berkumpul dalam kelompok ahli, untuk mendiskusikan topik mereka selama waktu yang ditentukan. Selanjutnya ahli-ahli ini kembali ke tim masing-masing untuk menyampaikan kepada anggota yang lain dalam satu tim asal. Pada akhirnya siswa mengerjakan kuis yang mencakup semua topik, selanjutnya kunci dari pembelajaran kooperatif tipe jigsaw adalah saling ketergantungan, yaitu setiap siswa bergantung pada anggota satu timnya untuk menyediakan imformasi yang dibutuhkan agar mengerjakan kuis dengan baik.

Peran guru dalam model pembelajaran cooperative tipe jigsaw adalah memfasilitasi dan memotivasi para anggota kelompok ahli agar mudah untuk memahami materi yang diberikan. Kunci tipe jigsaw ini adalah interdepence setiap siswa terhadap anggota tim. Menurut Slavin ${ }^{3}$ kegiatan intrusional yang secara regular dilaksanakan dalam pembelajaran kooperatif tipe jigsaw terdiri atas membaca, diskusi kelompok ahli, laporan tim, tes, dan penghargaan tim.

a. Membaca

\footnotetext{
3 Robert E. Slavin, Cooperative Learning (Cara Efektif dan Menyenangkan pacu Prestasi seluruh Peserta didik), (Bandung: Nusa Media, 2005), 122.
} 
Siswa menerima topik ahli dan membaca materi yang ditunjuk untuk menggali informasi (mendalaminya).

b. Diskusi kelompok ahli

Siswa dengan topik ahli yang sama bertemu untuk mendiskusikannya dalam kelompok ahli.

c. Laporan tim

Ahli-ahli kembali pada timnya dan mengerjakan topik mereka kepada anggota yang lain dalam satu timnya.

d. Tes

Siswa mengerjakan kuis individual yang mencakup semua topik.

e. Penghargaan tim

Tim dimungkinkan mendapatkan sertifikat atau penghargaan lain apabilaskor rata-rata mereka melebihi keriteria tertentu.

Adapun penilaian dalam pembelajaran kooperatif dilakukan dengan tes atau kuis tentang bahan pembelajaran. Dalam banyak hal, butir-butir tes pada kuis ini harus merupakan satu jenis tes obyektif paper and pencil, sehingga butir-butir itu dapat diskor di kelas atau segera setelah tes diberikan. Selanjutnya langkah-langkah dalam penerapan teknik jigsaw adalah sebagai berikut:

Guru membagi satu kelas menjadi beberapa kelompok, dengan setiap kelompok terdiri dari 4-6 siswa dengan kemampuan yang berbeda. Kelompok disebut kelompok asal. Jumlah anggota dalam kelompok asal menyesuaikan dengan jumlah bagian materi pelajaran yang akan dipelajari siswa sesuai dengan tujuan pembelajaran yang akan dicapai.Dalam tipe jigsaw ini, setiap siswa diberi tugas mempelajari salah satu bagian materi pembelajaran tersebut. Semua siswa dengan materi pembelajaran yang sama belajar bersama dalam dalam kelompok yang disebut ahli siswa mendiskusikan bagian materi pembelajaran yang sama, serta menyusun rencana bagaimana menyampaikan kepada temannya jika kembali ke kelompok asal. Kelompok asal ini oleh Aronson disebut kelompok jigsaw 
(gigi gergaji). Misal suatu kelas dengan jumlah 40 siswa dan materi pembelajaran yang akan dicapai sesuai dengan tujuan pembelajarannya terdiri dari 5 bagian materi pembelajaran, maka dari 40 siswa akan terdapat 5 kelompok ahli yang beranggotakan 8 siswa dan 8 kelompok asal yang terdiri dari 5 siswa. Setiap anggota kelompok ahli akan kembali ke kelompok asal memberikan informasi yang telah diperoleh atau dipelajari dalam kelompok ahli. Guru memfasilitasi diskusi kelompok baik yang ada pada kelompok ahli maupun kelompok asal.

\section{METODE PENELITIAN}

Suatu penelitian diperlukan suatu metode tertentu yang tepat dan sesuai dengan jenis penelitian yang dilakukan. Metode yang digunakan harus sesuai dengan masalah, sifat dan tujuan penelitian.Untuk itu dalam penelitian ini peneliti menggunakan metode deskriptif dengan pendekatan kualitatif. Hal ini karena penelitian ini dimaksudkan untuk mengungkap keadaan subjek penelitian sebagaimana adanya berdasarkan data yang dikumpulkan pada saat penelitian dilakukan.Penelitian kualitatif, karena menekankan pada keaslian, tidak bertolak dari teori secara deduktif (apriori) melainkan berangkat dari fakta sebagaimana adanya. Rangkaian fakta tersebut kemudian dikumpulkan, dikelompokkan, ditafsirkan, dan disajikan sehingga menghasilkan sebuah teori (grounded theory). Adapun sumber data dalam penelitian ini adalah seorang guru yang mengajar Aqidah Akhlak MIN Bangka belitung, sekaligus dijadikan sebagai sumber data utama atau data primer. Sedangkan sumber data pelengkap atau data sekunder dalam penelitian ini adalah beberapa siswa di MIN tersebut. Serta untuk melengkapi data dalam penelitian ini, peneliti juga akan melakukan pengamatan langsung pada pelaksanaan pembelajaran Aqidah Akhlak melalui buku yang ditentukan di sekolah MIN Bangka Belitung. Lokasi penelitian yang akan dilakukan oleh peneliti berada di MIN Bangka Belitung yang terdapat di Paris 1 kacamatan pontianak. Teknik yang peneliti 
yang digunakandalam penelitian ini adalah wawancara dan Dokumentasi. Sedangkan analisi data meliputi: pengumpulan data, reduksi data, penyajian data, penarikan kesimpulan dan verifikasi.

\section{HASIL DAN PEMBAHASAN TEMUAN}

Berdasarkan data-data dan informasi yang diperoleh melalui wawancara observasi dan studi dokomentasi dilapangan, maka dapat dilakukan pembahasan sebagai berikut :

1. Perencanaan Strategi Cooperative Learning Tipe JigsawDalam Pembelajaran Akidah Akhlak Pada Materi Akhlak Tercela Di Kelas V MIN Bangka Belitung Pontianakadalah dimana seorang guru harus mampu hasil wawancara dengan ibu Helyati, S. Pd.I sebagai berikut; dari perencanaan guru yang akan mengajar melakukan unsur-unsur RPP dimana didalamnya terdapat perencanaan-perencanaan oleh seorang guru pada mata pelajaran atau kelas yang menjadi tanggung jawabnya sangat penting. Demikian juga dengan perencanaan pembelajaran yang di empu oleh seorang guru. Perencanaan pembelajaran ibarat persiapan skenario dalam film. Tidak akan ada film yang baik, berkualitas, dan enak ditonton tanpa skenario yang baik dengan persiapan yagng matang. Begitu pula, tidak akan ada pembelajaran tanpa perencanaan yang matang”(Hasil wawancara,27 Agustus 2018).

2. Langkah-langkah Strategi Cooperative Learning Tipe JigsawDalam Mata Pelajaran Akidah Akhlak Pada Materi Akhlak Tercela Di Kelas V MIN Bangka Belitung Pontianak. Berdasarkan hasil wawancara diatas dengan ibu Helyati. S.Pd.I bahwa dalam proses pembelajaran sudah menggunakan strategi Coopera Tipe learningtipe jigsaw yang mana mengelompokkan siswa menjadi beberapa kelompok, dalam perencanaan pembelajaran dengan menggunakan strategi Cooperatipe Learningtipe Jigsaw ibu Helyati,S.Pd.I mengatakan sebagai berikut, "peranan seorang guru sangat penting untuk membentuk watak anak bangsa peranannya 
tidak dapat digantikan oleh apapun. Secanggih apapun teknologi tidak akan dapat menggantikan tugas-tugas guru yang cukup komleks dan unik. Maka dari itu, di perlukan guru profesional yang memiliki dedikasi tinggi dan bertanggung jawab terhadap tugas yang diembankan kepadanya. Guru profesional merupakan salah satu indikator penting dari sekolah berkualitas, karena dapat membantu proses pencapaian visi misi sekolah" (hasil wawancara, tanggal 22 Agustus 2018).

Guru membagi setiap kelas menjadi beberapa kelompok, dengan setiap kelompok terdiri dari 4-6 siswa dengan kemampuan yang berbeda. Kelompok tersebut di sebut kelompok asal. Jumlah anggota dalam kelompok asal menyesuian dengan jumlah bagian materi pelajaran. Yang akan di pelajari siswa denga tujua pembelajaran yang akan dicapai. Dalam tipe jigsaw ini, setiap siswa diberi tugas mempealajari bagian materi pembelajaran tersebut. Semua siswa dengan materi pembelajaran yang sama belajar bersama dalam kelompok yang disebut ahli siswa mendiskusiakan bagian materi pembelajaran yang sama, serta menyusun rencana bagaimana menyampaikan kepada temannya jika kembali kekelompok asal.

3. Pelaksanaan evaluasi proses dan hasil kegiatan pembelajaran yang menggunakan Strategi Cooperative Learning Tipe Jigsaw dalam Pembelajaran Akidah Akhlak Pada Materi Akhlak Tercela di Kelas V MIN Bangka Belitung Pontianak. Dari hasil Wawancara dengan Ibu Helyati S.Pd.I mengatakan sebagai berikut.Teknik tes merupakan salah satu alat, cara, dan langkah-langkah yang sistematik untuk digunakan dalam mengukur sejumlah perilaku tertentu siswa.berdasarkan cara pelaksanaan, teknik tes dikelompokkan sebagai berikut. Tes tertulis, yaitu alat penilaian yang bentuk dan pelaksanaannya dilakukan secara tertulis. Tes lisan, yaitu alat penilaian yang bentuk pelaksanaannya dilakukan secara lisan.Tes perbuatan,yaitu alat penelian yang baik pertanyaan maupun jawabannya dilakukan secara tertulis maupun lisan, seperti 
praktek dan laboratorium, praktek kesenian, simulasi, dan deklamasi (hasil wawancara tanggal 22 Agustus 2018). Jadi dalam Evaluasi pembelajaran guru menggunakan beberapa metode untuk melihat hasil dari pembelajaran tersebut Menurut Wiersma $^{4}$ bahwa evaluasi merupakan kegiatan mengukur dan mungkin juga berisi pengambilan keputusan tentang nilai. Pendapat ini sejalan dengan pendapat Arikunto (2009) yang menyatakan bahwa evaluasi merupakan kegiatan dan nilai. ${ }^{5}$ Pendapat ini sejaalan dengan pendapat Arikonto (2008) yang menyatkan bahwa evaluasi merupakan kegiatan mengukur dan menilai. Kedua pendapat di atas menanyakan secarainpisip menyatakan bahwa evaluasi memiliki cakupan yang lebih luas dari pada pengukuran dan testing.

Jadi evaluasi proses adalah suatu rangkaian kegiatan yang dilakukan dengan sengaja untuk melihat tingkat proses keberhasilan proses belajar atau pengajaran yang telah dilaksanakan. Dari sedikit uarian tersebut dapat di simpulakan bahwa suatu proses belajar atau pengajaran perlu dilakukan evaluasi supaya mengetahui tingkat kecapaian tujuan yang telah direncanakan sehingga dalam proses pengajaran ini menghasilkan peserta didik yang mempunayi aspek kognitif, apektif, dan psikomotorik yang tinggi serta berdampak pula terhadap keamjauan bangsa. Evaluasi penilaian hasl belajar. Penilaian hasil belajar adalah kegiatan atau cara yang di tujukan untuk mengetahui tercapai atau tidaknya tujuan pembelajaran dan juga proses pembealajaran yang telah di lakukan.

\section{SIMPULAN}

Penelitian ini mengkaji tentang pembelajaran kooperatif learningMerujuk pada seluruh analisis data dan pembahasan penelitian yang

\footnotetext{
${ }^{4}$ Wiesma. Strategi Pembelajaran Teori dan Praktek di Tingkat Pendidikan Dasar, (Jakarta: PT Raja Grapindo Persada, 1990), 9.

${ }^{5}$ Suharsimi Arikunto. Penelitian Tindakan Kelas, (Jakarta: Bumi Aksara, 2008).
} 
telah dipaparkan di atas, maka dikemukakan kesimpulan sebagai berikut: 1) Perencanaan Strategi Cooperative Learning Tipe Jigsawdalam Pembelajaran Akidah Akhlak Pada Materi Akhlak Tercela di Kelas V MIN Bangka Belitung Pontianakdengan lebih baik dan siswa lebih aktif dalam proses pembelajaran. 2) Langkah-langkah strategi cooperative learning tipe jigsaw dalam materi sikap siswa di sekolahdi kelas V MIN dibagi menjadi 5 kelompok, setiapkelompok diksih materi pembelajaran, dan siswa mendiskusikan dengan materi tersebut. 3) Pelaksanaan evaluasi proses dan hasil kegiatan pembelajaran yang menggunakan langkah strategi cooperative learning tipe jigsaw dalam materi sikap siswa di sekolahdi kelas V MIN Negeri Bangka Belitung Pontianak adalah menggunakan tes tertulis dan tes lisan juga mengunakan penilain proses dari observasi siswa saat proses pembelajaran atau setelah mata kuliah selesai.

\section{DAFTAR PUSTAKA}

Arikunto, Suharsimi. Penelitian Tindakan Kela, Jakarta: Bumi Aksara, 2008.

Departemen Agama RI. Standar Penilaian Di Kelas, Jakarta: Direktorat Jenderal Kelembagaan Agama Islam Direktorat Madrasah dan Pendidikan Agama Islam pada Sekolah Umum, 2003.

Guntur, Setiawan. Impelemtasi dalam Birokrasi Pembangunan. Jakarta: Balai Pustaka, 2004.

Uno, Hamzah. Perencanaan Pembelajaran. Jakarta: Bumi Aksara

Handari, Nawawi. Metode Penelitian Bidang Sosial, Pontianak: Gajah Mada University Press, 2012.

Hisyam Zaini, et,al. Strategi Pembelajaran AKtif, Yogyakarta: Pustaka Insan Madani, 2002.

Moleong, Lexy. J. Metode Penelitian Kualitatif. Bandung: PT Rosada Karya, 2002.

Nurdin, Usman. Konteks Implementasi Berbasis Kurikulum. Jakarta: Grasindo, 2002.

Hamalik, Oemar. Proses Belajar Mengajar. Jakarta: Bumi Aksara, 2008. 
Peraturan Menteri Agama Republik Indonesia Nomor 2 Tahun 2008 tentang Standar Kompetensi Lulusan Dan Standar Isi Pendidikan Agama Islam Dan Bahasa Arab Di Madrasah.

Peraturan Menteri Agama Republik Indonesia Nomor 2 Tahun (2008). tentang Standar Kompetensi Lulusan dan Standar Isi Pendidikan Agama Islam Dan Bahasa Arab Di Madrasah.

Rahman et,al. 2012. Metode pembelajaran jigsaw. Diakses 20 Mei 2015

Rusman. Seri Manajemen Sekolah Bermutu Model-Model Pembelajaran Mengembangkan Profesionalisme Guru, Jakarta; PT. Raja Grafindo Persada, 2018.

Slavin, Robert E. . Cooperative Learning (Cara Efektif dan Menyenangkan pacu Prestasi seluruh Peserta didik). Bandung: Nusa Media, 2005.

Sudrajat, Akhmad. 2008. Cooperative Learning-teknik Jigsaw. http://akhmadsudrajat.wordpress.com.

Sugianto. Model-model Pembelajaran Inovatif. Surakarta: Yuma Pustaka, 2010.

Sugiyono. Metode Penelitian Pendidikan (Pendekatan Kuantitatif, Kualitatif, dan R\&D), Bandung: Alfabeta, 2012.

Wierma, W. Educational MeasuaramentAnd Testing, Boston: Allyn End Bacon, 1990.

Wiesma. Strategi Pembelajaran Teori dan Praktek di Tingkat Pendidikan Dasar. Jakarta: PT Raja Grapindo Persada, 1990.

Zaini, Hisyamdkk. Strategi Pembelajaran Aktif. Yogyakarta: Pustaka Insan Madani, 2008.

Zuldafrial. Penelitian Kualitatif. Pontianak: STAIN Press, 2011. 